\title{
PESQUISA QUALITATIVA: ANÁLISE DE DISCURSO VERSUS ANÁLISE DE CONTEÚDO ${ }^{1}$ QUALITATIVE RESEARCH: DISCOURSE ANALYSIS VERSUS CONTENT ANALYSIS INVESTIGACIÓN CUALITATIVA: ANÁLISIS DEL DISCURSO VERSUS ANÁLISIS DEL CONTENIDO
}

\author{
Rita Catalina Aquino Caregnato², Regina Mutti
}

${ }^{1}$ Artigo produzido como trabalho de conclusão da disciplina "Práticas de Análise de Discurso na Pesquisa em Educação", do 1- semestre de 2005, ministrada pela Professora Regina Mutti, do Programa de Pós-Graduação em Educação (FACED) da Universidade Federal do Rio Grande do Sul (UFRGS).

${ }^{2}$ Enfermeira. Doutoranda em Educação pela UFRGS. Mestre em Enfermagem pela UFRGS. Professora da Graduação e PósGraduação em Enfermagem da Universidade Luterana do Brasil (ULBRA). Professora de Graduação em Enfermagem do Centro Universitário do Vale do Taquari (Centro Universitário UNIVATES).

${ }^{3}$ Mestre e Doutora em Letras. Professora do Programa de Pós-Graduação em Educação da UFRGS, na disciplina "Práticas de Análise de Discurso na Pesquisa em Educação". Orientadora deste artigo.

PALAVRAS-CHAVE: Enfermagem. Pesquisa qualitativa. Análise qualitativa.
RESUMO: Considerando o crescente interesse nas pesquisas qualitativas na área de Enfermagem, acreditase ser importante o conhecimento de diferentes formas de análise existentes. Este artigo tem como objetivo fazer uma reflexão sobre dois tipos de análise utilizada freqüentemente na pesquisa qualitativa, algumas vezes confundidas. Apresenta-se uma fundamentação teórica da Análise de Discurso e da Análise de Conteúdo e se expõe as diferenças entre estas duas formas de análise. A principal diferença é que a Análise de Discurso trabalha com o sentido do discurso e a Análise de Conteúdo com o conteúdo do texto. A opção teórica da Análise de Discurso abordada neste estudo recai sobre a linha francesa, que tem como seu precursor Michel Pêcheux e na Análise de Conteúdo enfoca-se Laurence Bardin.
KEYWORDS: Nursing. Qualitative research. Qualitative analysis.
ABSTRACT: Considering the increasing interest in qualitative research in Nursing, we consider it relevant to know the different approaches to this analysis. This article has the objective to discuss the two kinds of approach often used in qualitative research, which is sometimes confused. A theoretical foundation is presented, in which Discourse Analysis and Content Analysis show the differences between the two forms of analysis. The main difference is that discourse analysis works with the meaning of the discourse, and content analysis works with the content of the text This study's theoretical option for Content Analysis follows the French approach, which has Pêcheux as its precursor and the content analysis is based on Laurence Bardin.
PALABRAS CLAVE: Enfermería. Investigación cualitativa. Análisis cualitativo.
RESUMEN: Considerando el creciente interés en las investigaciones cualitativas en el área de la Enfermería, se cree que es importante el conocimiento de las diferentes formas de análisis que existem. Este artículo tiene como objetivo hacer una reflexión sobre los dos tipos de análisis utilizados frecuentemente en la investigación cualitativa, algunas veces confusas. Se presenta un fundamento teórico del Análisis del Discurso y el Análisis del Contenido e se expone las diferencias entre las dos formas de análisis. La principal diferencia es que el Análisis del Discurso trabaja con el sentido del discurso y el Análisis del Contenido con el contenido del texto. La opción teórica del Análisis del Discurso tratada en éste estudio sobrecae em la linea francesa, que tiene como su precursor a Michel Pêcheux y el Análisis del Contenido enfoca a Laurence Bardin.
Endereço: Rita Catalina Aquino Caregnato

R. Dr. Rodrigues Alves, 273, Ap. 203

91.330-240 - Chácara das Pedras, Porto Alegre, RS.

E-mail: carezuca@terra.com.br
Artigo original: Reflexão teórica Recebido em: 24 de abril de 2006. Aprovação final: 13 de outubro de 2006. 


\section{INTRODUÇÃO}

Atuando como professora universitária na graduação da Enfermagem há mais de uma década, e como orientadora de monografias tanto da graduação como na Pós-Graduação, tenho observado alunos, e até mesmo colegas, utilizando como sinônimos a Análise de Discurso e a Análise de Conteúdo. Esta freqüente confusão ocorreu até mesmo comigo, quando iniciei minha trajetória acadêmica, expressando algumas vezes a nomenclatura destas duas formas de análise como se fossem similares. Por ocasião da minha dissertação tive a oportunidade de conhecer, aprofundar e colocar em prática a Análise de Conteúdo de Bardin, a qual foi por mim utilizada para interpretar os dados da minha pesquisa. ${ }^{1}$ Ao ingressar na Faculdade de Educação, para cursar doutorado, minha curiosidade científica recaiu na Análise de Discurso (AD), fazendo com que buscasse disciplinas no intuito de conhecer este tipo de análise e posteriormente utilizá-la na minha tese.

Este artigo tem como objetivo fazer uma reflexão sobre a Análise de discurso e a Análise de Conteúdo freqüentemente utilizadas na pesquisa qualitativa e por vezes confundidas. Tenho percebido que a pesquisa qualitativa vem conquistando um espaço crescente na área de Enfermagem; conseqüentemente, acredito ser de extrema relevância ter clareza sobre as diferenças entre essas duas formas de análise.

\section{APRESENTANDO A ANÁLISE DE DIS- CURSO (AD) DA LINHA FRANCESA}

Não existe apenas uma linha de Análise de Discurso; existem muitos estilos diferentes "provavelmente ao menos 57 variedades de análise de discurso", 2:246 com enfoques variados, a partir de diversas tradições teóricas, porém todas reivindicando o mesmo nome. $\mathrm{O}$ que esses diferentes estilos parecem ter em comum, ao tomar como objeto o discurso, é que partilham de "uma rejeição da noção realista de que a linguagem é simplesmente um meio neutro de refletir, ou descrever o mundo, e uma convicção da importância central do discurso na construção da vida social”. 2:244

Existe uma reserva em dizer "Escola" de Análise de Discurso francesa, porque se questiona o sentido que pode tomar a palavra "Escola". Como a AD considera a língua, história e sujeito, e cada país tem sua própria língua e história, então poderíamos "falar em análise de discurso germânica, americana, inglesa, italiana, brasileira, francesa etc, se pensamos nessa disciplina sendo desenvolvida em diferentes regiões do mundo com suas diferentes tradições de estudos e pesquisas sobre o discurso" 3 3:1 É reforçada a idéia de que o conhecimento produz relações de força e de poder; por isso, ao se dizer "Escola" de análise de discurso, francesa ou anglófona, está se atribuindo um poder privilegiando certos lugares. ${ }^{3}$ Importante lembrar que "a ciência se produz em diferentes lugares com a força e a especificidade de sua tradição" $3: 2$

$\mathrm{A} A \mathrm{AD}$ não é uma metodologia, é uma disciplina de interpretação fundada pela intersecção de epistemologias distintas, pertencentes a áreas da lingüística, do materialismo histórico e da psicanálise..$^{3-4}$ Essa contribuição ocorreu da seguinte forma: da lingüística deslocou-se a noção de fala para discurso; do materialismo histórico emergiu a teoria da ideologia; e finalmente da psicanálise veio a noção de inconsciente que a $\mathrm{AD}$ trabalha com o de-centramento do sujeito. ${ }^{3}$

O processo de análise discursiva tem a pretensão de interrogar os sentidos estabelecidos em diversas formas de produção, que podem ser verbais e não verbais, bastando que sua materialidade produza sentidos para interpretação; podem ser entrecruzadas com séries textuais (orais ou escritas) ${ }^{4}$ ou imagens (fotografias) ou linguagem corporal (dança). ${ }^{5}$

Um dos fundadores dos estudos sobre o discurso foi Michel Pêcheux, estabelecendo a relação existente no discurso entre língua/sujeito/história ou língua/ideologia; portanto, quem segue este princípio pode afirmar uma filiação com a AD da linha francesa. ${ }^{3}$

O suporte teórico que embasa este texto refere-se à $\mathrm{AD}$ da linha francesa, que "articula o lingüístico com o social e o histórico", $6: 192$ na qual a linguagem é estudada não apenas enquanto forma lingüística como também enquanto forma material da ideologia. ${ }^{6}$ Além de que é "no contato do histórico com o lingüístico, que [se] constitui a materialidade específica do discurso" $7: 8$

A $\mathrm{AD}$ trabalha com o sentido e não com o conteúdo do texto, um sentido que não é traduzido, mas produzido; pode-se afirmar que o corpus da $\mathrm{AD}$ é constituído pela seguinte formulação: ideologia + história + linguagem. A ideologia é entendida como o posicionamento do sujeito quando se filia a um discurso, sendo o processo de constituição do imaginário que está no inconsciente, ou seja, o sistema de idéias que constitui a representação; a história 
representa o contexto sócio histórico e a linguagem é a materialidade do texto gerando "pistas" do sentido que o sujeito pretende dar. Portanto, na AD a linguagem vai além do texto, trazendo sentidos pré-construídos que são ecos da memória do dizer. Entende-se como memória do dizer o interdiscurso, ou seja, a memória coletiva constituída socialmente; o sujeito tem a ilusão de ser dono do seu discurso e de ter controle sobre ele, porém não percebe estar dentro de um contínuo, porque todo o discurso já foi dito antes. Exemplificando, com o olhar da AD o enunciado "é dando que se recebe" permite uma multiplicidade de sentidos. Este pode ser pronunciado tanto por um padre franciscano, quanto por um político ou por uma prostituta, com sentidos diferentes para cada sujeito. A fonte originária deste enunciado foi o discurso religioso, permanecendo no contexto sócio histórico e ficando na memória do dizer, ou memória discursiva, e voltando em um novo contexto, de outro momento histórico, com novas significações, perdendo o sentido religioso e popularizando-se no sentido político e vulgar.*

A língua é considerada opaca e heterogênea, conseqüentemente, ela não é transparente e homogênea como muitas vezes aparenta ser; isto faz com que ela seja "capaz de equívoco, de falha, de deslizes" . ${ }^{6: 192} \mathrm{O}$ equívoco é contra a idéia do sentido único do enunciado; este permite leituras múltiplas. O sentido não está “colado" na palavra, é um elemento simbólico, não é fechado nem exato, portanto sempre incompleto; por isso o sentido pode escapar. O enunciado não diz tudo, devendo o analista buscar os efeitos dos sentidos e, para isso, precisa sair do enunciado e chegar ao enunciável através da interpretação.

A AD não abre mão da língua, embora não tenha o mesmo enfoque abordado por Saussure. Para Pêcheux a língua é a forma de materialização da fala, contando com os planos material e simbólico; o discurso produzido pela fala sempre terá relação com o contexto sócio histórico. Exemplificando com o discurso de um político, que parte de uma ideologia política, Pêcheux diz: “em outras palavras, um discurso é sempre pronunciado a partir de condições de produção dadas: por exemplo, o deputado pertence a um partido político que participa do governo ou a um partido da oposição; é porta-voz de tal ou tal grupo que representa tal ou tal interesse [...]. Isto supõe que é impossível analisar um discurso como um texto, isto é, como uma seqüência lingüística fechada sobre si mesma, mas que é necessário referí-lo ao conjunto de discursos possíveis a partir de um estado definido das condições de produção [...]". 8:77-9

Portanto, como se verifica nas colocações de Pêcheux, a AD entende que "todo dizer é ideologicamente marcado". 9:38 Neste contexto o sujeito não é individual, é assujeitado ao coletivo, ou seja, esse assujeitamento ocorre no nível inconsciente, quando o sujeito se filia-se ou interioriza o conhecimento da construção coletiva, sendo porta-voz daquele discurso e representante daquele sentido. Entende-se como assujeitamento em AD o "[...] movimento de interpelação dos indivíduos por uma ideologia, condição necessária para que o indivíduo torne-se sujeito do seu discurso ao, livremente, submeter-se às condições de produção impostas pela ordem superior estabelecida, embora tenha ilusão de autonomia”. ${ }^{10: 12}$

Partindo do princípio que a $\mathrm{AD}$ trabalha com o sentido, sendo o discurso heterogêneo marcado pela história e ideologia, a $\mathrm{AD}$ entende que não irá descobrir nada novo, apenas fará uma nova interpretação ou uma re-leitura; outro aspecto a ressaltar é que a $\mathrm{AD}$ mostra como o discurso funciona não tendo a pretensão de dizer o que é certo, porque isso não está em julgamento.

A formação discursiva constitui-se na relação com o interdiscurso e o intradiscurso. ${ }^{11} \mathrm{O}$ interdiscurso significa os saberes constituídos na memória do dizer; sentidos do que é dizível e circula na sociedade; saberes que existem antes do sujeito; saberes pré-construídos constituídos pela construção coletiva. $O$ intradiscurso é a materialidade (fala), ou seja, a formulação do texto; o fio do discurso; a linearização do discurso.

A interpretação do discurso "é um 'gesto', ou seja, é um ato no nível simbólico. [...] A interpretação é o vestígio do possível. É o lugar próprio da ideologia e é 'materializada' pela história. [...] Ela sempre se dá de algum lugar da história e da sociedade [...]" ${ }^{11: 18-9} \mathrm{O}$ gesto de interpretação é assumido, sendo um gesto simbólico que dá sentido

Mutti RMV. Fundamentos e Procedimentos em Análise de Discurso [aula expositiva da disciplina]. Porto Alegre (RS): UFRGS/ PPGFACED; 2004, $2^{\circ}$ semestre. 
fazendo a significação. "Não há sentido sem interpretação", 3:11,11:21 portanto deverá sempre existir uma interpretação para dar visibilidade ao sentido que o sujeito pretendeu transmitir no seu discurso.

$\mathrm{Na}$ interpretação é importante lembrar que o analista é um intérprete, que faz uma leitura também discursiva influenciada pelo seu afeto, sua posição, suas crenças, suas experiências e vivências; portanto, a interpretação nunca será absoluta e única, pois também produzirá seu sentido.

Vamos supor, por exemplo, que o analista disponha-se ao enfoque da posição de professor, no discurso pedagógico de uma disciplina do curso de Enfermagem. Para constituir o corpus para análise, representativo desse discurso, decide ouvir os professores em entrevistas fazendo a transcrição da gravação feita; não há um caminho pronto para efetivar a análise, mas após várias leituras poderão ser identificados eixos temáticos, que emergem num movimento em que o enunciado leva ao enunciável e vice-versa, explorando-se marcas lingüísticas cujo funcionamento discursivo irá trabalhar, fazendo os recortes das formulações nas quais aparece tal ênfase. Cabe informar o enfoque analítico que é dado à pesquisa. Qualquer elemento pode ser estudado enquanto marca lingüística, ou "marca de discurso", podendo ser selecionadas poucas marcas lingüísticas para interpretação; na $\mathrm{AD}$ não é necessário analisar tudo que aparece na entrevista, pois se trata de uma análise vertical e não horizontal. $\mathrm{O}$ importante é captar a marca lingüística e relacioná-la ao contexto sócio-histórico. Deste modo, várias leituras do texto farão com que o analista do discurso estranhe aquela(s) palavra(s) ou formas sintáticas, pode ser, que $\operatorname{marca}(\mathrm{m})$ o discurso e se repete(m), visualizando assim as marcas lingüísticas no material linguageiro.

Também é interessante explicar o motivo que induziu a escolha do recorte sócio-histórico, pois este faz parte das "condições" de produção do discurso, representadas no corpus em análise, bem como a necessidade de ilustrar as condições da constituição do corpus. ${ }^{8}$ Após ter delimitado o eixo temático o analista irá trabalhar com este, o que supõe o estabelecimento de "recortes discursivos", onde se representam linguagem e situação. O recorte resulta da teoria e é uma construção do analista; no estudo do recorte se busca caracterizar as regularidades na "formação discursiva", no confronto com sentidos heterogêneos. ${ }^{11}$ As regularidades das marcas lingüísticas que aparecem no discurso fazem parte da identidade do discurso acessado pelo sujeito, trazendo sentidos pré-construídos que figuram na memória do dizer da sociedade.

A interpretação deverá ser feita sempre entre o interdiscurso e o intradiscurso chegando às posições representadas pelos sujeitos através das marcas lingüísticas. $\mathrm{A} A \mathrm{AD}$ não vai trabalhar com a forma e o conteúdo, mas irá buscar os efeitos de sentido que se pode apreender mediante interpretação. Nunca esquecer que a interpretação sempre é passível de equívoco, pois embora a interpretação pareça ser clara, na realidade existem muitas e diferentes definições, sendo que os sentidos não são tão evidentes como parecem ser. ${ }^{11}$ Pêcheux reforça a $A D$ "sob o prisma de uma leitura interpretativa". ${ }^{7,10: 94}$ Embora a AD "seja mais relevante para as ciências da linguagem, ela está presente no exercício das ciências humanas"; portanto, a interpretação caberá tanto ao "analista da linguagem quanto à do cientista em geral". 11:9

\section{CONSIDERAÇÕES SOBRE A ANÁLISE DE CONTEÚDO}

A Análise de Conteúdo (AC) surgiu no início do século XX nos Estados Unidos para analisar o material jornalístico, ocorrendo um impulso entre 1940 e 1950, quando os cientistas começaram a se interessar pelos símbolos políticos, tendo este fato contribuído para seu desenvolvimento; entre 1950 e 1960 a AC estendeu-se para várias áreas..$^{12}$ Portanto, esta técnica "existe há mais de meio século em diversos setores das ciências humanas", sendo anterior a Análise de Discurso. ${ }^{12: 54}$

A definição da AC em 1943 era como sendo “a semântica estatística do discurso político" ${ }^{13: 192}$ A AC pode ser quantitativa e qualitativa. Existe uma diferença entre essas duas abordagens: na abordagem quantitativa se traça uma freqüência das características que se repetem no conteúdo do texto. ${ }^{1} \mathrm{Na}$ abordagem qualitativa se "considera a presença ou a ausência de uma dada característica de conteúdo ou conjunto de características num determinado fragmento da mensagem". ${ }^{12: 54}$

A maioria dos autores refere-se à AC como sendo uma técnica de pesquisa que trabalha com a palavra, permitindo de forma prática e objetiva produzir inferências do conteúdo da comunicação de um texto replicáveis ao seu contexto social. ${ }^{13} \mathrm{Na}$ AC o texto é um meio de expressão do sujeito, onde o analista busca categorizar as unidades de texto (palavras ou frases) que se repetem, inferindo uma expressão que as representem. 
A crescente utilização da Análise de Conteúdo na área da Enfermagem é evidenciada em muitos trabalhos publicados, em várias revistas de circulação nacional e internacional, que utiliza-se da Análise de Conteúdo na sua pesquisa em gerontologia para interpretar os dados coletados no período de 1975-1996. ${ }^{14}$

Para Laurence Bardin, escolhida neste artigo como referencial devido à ampla utilização desta autora nas pesquisas de Enfermagem, a AC é "um conjunto de técnicas de análise das comunicações visando obter, por procedimentos, sistemáticos e objetivos de descrição do conteúdo das mensagens, indicadores (quantitativos ou não) que permitam a inferência de conhecimentos relativos às condições de produção/recepção [...] destas mensagens". 1:42

No texto em que marca a diferença teórica entre conteúdo e sentido, a AC costuma ser feita através do método de dedução freqüencial ou análise por categorias temáticas. ${ }^{8} \mathrm{~A}$ dedução freqüencial consiste em enumerar a ocorrência de um mesmo signo lingüístico (palavra) que se repete com freqüência, visando constatar "a pura existência de tal ou tal material lingüístico", 8:64 não preocupando-se com o "sentido contido no texto, nem à diferença de sentido entre um texto e outro", 8:65 culminando em descrições numéricas e no tratamento estatístico. ${ }^{13}$ A análise por categorias temáticas tenta encontrar "uma série de significações que o codificador detecta por meio de indicadores que lhe estão ligados; [...] codificar ou caracterizar um segmento é colocá-lo em uma das classes de equivalências definidas, a partir das significações, [...] em função do julgamento do codificador [...] o que exige qualidades psicológicas complementares como a fineza, a sensibilidade, a flexibilidade, por parte do codificador para apreender o que importa” 8:65

A análise categorial é o tipo de análise mais antiga e na prática a mais utilizada. "Funciona por operações de desmembramento do texto em unidades, em categorias segundo reagrupamento analógicos”. 1:153 A análise categorial poderá ser temática, construindo as categorias conforme os temas que emergem do texto. ${ }^{1}$ Para classificar os elementos em categorias é preciso identificar o que eles têm em comum, permitindo seu agrupamento. ${ }^{1}$ Este tipo de classificação é chamado de análise categorial. ${ }^{1}$
A técnica de AC, se compõe de três grandes etapas: 1) a pré-análise; 2) a exploração do material; 3) o tratamento dos resultados e interpretação. ${ }^{1}$ A mencionada autora descreve a primeira etapa como a fase de organização, que pode utilizar vários procedimentos, tais como: leitura flutuante, hipóteses, objetivos e elaboração de indicadores que fundamentem a interpretação. $\mathrm{Na}$ segunda etapa os dados são codificados a partir das unidades de registro. $\mathrm{Na}$ última etapa se faz a categorização, que consiste na classificação dos elementos segundo suas semelhanças e por diferenciação, com posterior reagrupamento, em função de características comuns. Portanto, a codificação e a categorização fazem parte da AC.

\section{DIFERENÇAS ENTRE ANÁLISE DO DIS- CURSO E ANÁLISE DE CONTEÚDO}

Sobre a análise de conteúdo e a teoria do discurso, referindo-se a análise de conteúdo como sinônimo da análise de texto ${ }^{\dagger}$ percebe-se "que antes de tudo a diferença entre a $\mathrm{AD}$ e a $\mathrm{AC}$ é o modo de acesso ao objeto". $8: 68$

A interpretação da $\mathrm{AC}$ poderá ser tanto quantitativa quanto qualitativa, enquanto que na $\mathrm{AD}$ a interpretação será somente qualitativa.

"A AC trabalha tradicionalmente com materiais textuais escritos”. ${ }^{13: 195}$ Existem dois tipos de textos que podem ser trabalhados pela AC: os textos produzidos em pesquisa, através das transcrições de entrevista e dos protocolos de observação, e os textos já existentes, produzidos para outros fins, como textos de jornais. ${ }^{13} \mathrm{Na} \mathrm{AD}$ existe o corpus de arquivo e empírico. Quando se analisa em AD material já existente como documentos, legislação, pronunciamentos em jornal, livros e outros, refere-se ao corpus de arquivo; se o material é construído especialmente para a pesquisa, como por exemplo, através de entrevista, refere-se ao corpus empírico, experimental.

A maior diferença entre as duas formas de análises é que a $\mathrm{AD}$ trabalha com o sentido e não com o conteúdo; já a AC trabalha com o conteúdo, ou seja, com a materialidade lingüística através das condições empíricas do texto, estabelecendo

† Itálico usado por Pêcheux no texto Análise automática do discurso (1969). In: Gadet F, Hak T (organizadores). Por uma análise automática do discurso: uma introdução à obra de Michel Pêcheux. 2a ed. Campinas (SP): Editora da Unicamp; 1993, p 63. 
categorias para sua interpretação. Enquanto a AD busca os efeitos de sentido relacionados ao discurso, a AC fixa-se apenas no conteúdo do texto, sem fazer relações além deste. A AD preocupa-se em compreender os sentidos que o sujeito manifesta através do seu discurso; já a AC espera compreender o pensamento do sujeito através do conteúdo expresso no texto, numa concepção transparente de linguagem. $\mathrm{Na} \mathrm{AD}$, a linguagem não é transparente, mas opaca, por isso, o analista de discurso se põe diante da opacidade da linguagem.

$\mathrm{O}$ analista ao utilizar a AD fará uma leitura do texto enfocando a posição discursiva do sujeito, legitimada socialmente pela união do social, da história e da ideologia, produzindo sentidos. Na utilização da AC "o que é visada no texto é justamente uma série de significações que o codificador detecta por meio dos indicadores que lhe estão ligados". 8:65

\section{CONCLUSÕES}

$\mathrm{Na}$ reflexão realizada, conforme fundamentação teórica apresentada, destaca-se como principal diferença entre as duas formas de análise abordadas que a Análise de Discurso trabalha com o sentido do discurso e a Análise de Conteúdo com o conteúdo do texto.

"A grande maioria das pesquisas sociais se baseia na entrevista", ${ }^{13: 189}$ encontrar uma forma ideal para interpretar esses dados é utópico. Acredita-se que não exista uma análise melhor ou pior, o importante é que o pesquisador conheça as várias formas de análise existentes na pesquisa qualitativa e sabendo suas diferenças, permitirá uma escolha consciente do referencial teórico-analítico, decorrente do tipo de análise que irá empregar na sua pesquisa, fazendo sua opção com responsabilidade e conhecimento.

\section{REFERÊNCIAS}

1 Bardin L. Análise de conteúdo. Lisboa: Edições 70; 1977.
2 Gill R. Análise de Discurso. In: Bauer MW, Gaskell G. Pesquisa qualitativa com texto, imagem e som: um manual prático. 3a ed. Petrópolis (RJ): Vozes; 2002. p.244-70.

3 Orlandi EP. A Análise de discurso em suas diferentes tradições intelectuais: o Brasil. In: Anais do 10 Seminário de Estudos em Análise de Discurso; 2003 Nov 10-13; Porto Alegre, Brasil [CD-ROM]. Porto Alegre (RS): UFRGS; 2003.

4 Mutti R. O primado do outro sobre o mesmo... . In: Anais do 10 Seminário de Estudos em Análise de Discurso; 2003 Nov 10-13; Porto Alegre, Brasil [CDROM]. Porto Alegre (RS): UFRGS; 2003.

5 Orlandi EP, organizadora. Cidade atravessada: os sentidos públicos no espaço urbano. Campinas (SP): Pontes; 2001.

6 Melo EAS. Gestos de autoria: construção do sujeito da escrita na alfabetização. In: Baronas RL, organizador. Identidade cultura e linguagem. Campinas (SP): Pontes Editores; 2005. p.191-205.

7 Pêcheux M. O Discurso: estrutura ou acontecimento. 3a ed. Campinas (SP): Pontes; 2002.

8 Pêcheux M. Análise automática do discurso (AAD-69). In: Gadet F, Hak T, organizadores. Por uma análise automática do discurso: uma introdução à obra de Michel Pêcheux. 2a ed. Campinas (SP): Ed Unicamp; 1993. p.61-105.

9 Orlandi EP. Análise de Discurso: princípios e procedimentos. Campinas (SP): Pontes; 1999.

10 Ferreira MCL. Apresentação. In: Glossário de termos do discurso. Ferreira MCL, coordenadora. Porto Alegre (RS): UFRGS; 2001. p.5-7.

11 Orlandi E. Interpretação: autoria, leitura e efeitos do trabalho simbólico. 4a ed. Campinas (SP): Pontes; 2004.

12 Lima MADS. Análise de conteúdo:estudo e aplicação. Rev Logos 1993; (1): 53-8.

13 Bauer MW. Análise de conteúdo clássica: uma revisão. In: Bauer MW, Gaskell G. Pesquisa qualitativa com texto, imagem e som: um manual prático. 3a ed. Petrópolis (RJ): Vozes; 2002. p.189-217.

14 Neri AL. A pesquisa em gerontologia no Brasil: análise de conteúdos de amostra de pesquisa em psicologia no período de 1975-1996. Texto Contexto Enferm.1997 Maio-Ago; 6 (2): 69-105. 